\title{
LA INSERCIÓN DE LAS COMUNIDADES DE FIELES EN LOS ORDENAMIENTOS SECULARES. EVALUACIÓN DEL RÉGIMEN LEGAL CHILENO SOBRE CONSTITUCIÓN DE ENTIDADES RELIGIOSAS Y ESTUDIO PRELIMINAR DE SUS FUNDAMENTOS CONCEPTUALES
}

\author{
THE INSERTION OF COMMUNITIES OF WORSHIPERS INTO \\ SECULAR LEGAL SYSTEMS. ASSESSMENT OF THE CHILEAN LEGAL \\ SYSTEM ON THE CONSTITUTION OF RELIGIOUS ORGANIZATIONS \\ AND PRELIMINARY STUDY OF ITS CONCEPTUAL FOUNDATIONS
}

\author{
Jorge Del Picó RUBio ${ }^{1}$
}

\begin{abstract}
RESUMEN: El trabajo aborda el problema de la inserción de las colectividades organizadas de fieles de las principales religiones contemporáneas en los sistemas normativos jurídicos occidentales. En particular, analiza el tránsito de las comunidades de fieles hacia formas organizativas sociales, centrándose en el sistema chileno instaurado por la ley 19.638, de 1999, sobre constitución de entidades religiosas como personas jurídicas de derecho público, cuya efectividad evalúa positivamente.
\end{abstract}

Palabras clave: Derecho y religión - instituciones religiosas - secularismo (Thesaurus) - Ley de Cultos (Chile) - personas jurídicas religiosas

ABSTRACT: This paper addresses the problem of the insertion of organized groups of worshipers of the main contemporary religions into western legal systems. It particularly deals with the transition of communities of worshipers towards the constitution of social organizations, focusing on the Chilean system established by Law 19.638, of 1999, on the constitution of religious organizations as legal persons governed by public law, whose effectiveness has received a positive evaluation.

Keywords: Law and religion - Religious institutions - Secularization - Law 19.638 (Chile) Religious legal persons

\section{INTRODUCCIÓN}

El reconocimiento estatal de la organización social de los fieles de las confesiones religiosas, en adelante las "comunidades de fieles", ha oscilado en la era moderna entre la plena identificación de una determinada confesión con el Estado -lo que ha dado lugar a los sistemas confesionales de unión entre la Iglesia y el Estado en Occidente, incluyendo la prohibición en no pocas oportunidades del culto de cualquiera otra- hasta la separación

Doctor en Derecho de la Universidad de Zaragoza; Profesor asociado de Derecho Civil y Ciencias del Derecho en la Universidad de Talca (Chile). Dirección postal: Facultad de Ciencias Jurídicas y Sociales, Universidad de Talca, Campus Lircay s/n, Lircay, Talca. Dirección electrónica: jlp@utalca.cl 
radical de los ámbitos religioso y jurídico, eximiendo o negando -según la perspectiva que se asuma- todo tipo de reconocimiento público a las organizaciones eclesiásticas. Sin embargo, la tendencia en las últimas décadas en Iberoamérica ha seguido una ruta intermedia entre ambas posturas, dando lugar a sistemas legales de reconocimiento de la personalidad jurídica de las organizaciones religiosas, enmarcados dentro del proceso de consagración progresiva de la plena libertad religiosa y de culto, realidad que en gran medida es el resultado de un largo camino iniciado por los fieles de las confesiones minoritarias con el objetivo de lograr un estatus jurídico civil y, luego, el reconocimiento legal de la igualdad jurídica de todas las entidades religiosas por parte del Estado.

El planteamiento del problema expuesto en este trabajo se enmarca en la valoración pública del fenómeno religioso como una unidad indisoluble, constituida por las creencias, el culto, los modos de vida y la organización, además del ordenamiento normativo accesorio a los elementos precedentes. La religión, así considerada, no queda restringida a la esfera de la interioridad personal sino que determina conductas individuales y colectivas externamente relevantes, toda vez que el ser humano construye comunidades, modela formas de comprensión del mundo que le rodea e interviene en la historia partiendo de su vida religiosa personal, elaborando sobre esta base "referentes éticos y morales", todo lo cual determina que no se pueda separar a la religión de la sociedad, del mismo modo que no es posible separar "al creyente de su comunidad, ni a la comunidad de su organización"2.

El artículo postula que, en el caso de Chile, las comunidades de fieles se han situado efectivamente dentro de la realidad pública y sus ordenamientos normativos se rigen por los ordenamientos seculares de naturaleza jurídica, tanto en el nivel constitucional como en el plano legal del orden normativo, a los cuales han debido adaptarse constituyendo un ejemplo de inserción social eficaz ${ }^{3}$. El trabajo, considerando esta hipótesis, analiza la inserción de las comunidades de fieles correspondientes a las principales confesiones religiosas chilenas, en el sistema establecido por la ley $\mathrm{N}^{\circ} 19.638$, de 1999 , con el objetivo de confirmar la realidad de dicha inserción y evaluar la eficacia legislativa y reglamentaria en el proceso constitutivo de las entidades religiosas como personas jurídicas de derecho público y en su acción posterior como entidades civiles ya conformadas. Contribuyen a la comprensión cabal de dicho logro, la revisión de los fundamentos conceptuales del sistema aplicado y el análisis cualitativo de los resultados obtenidos de un reciente estudio de campo dirigido por el autor de estas líneas, y cuyo propósito ha sido precisamente evaluar dicho régimen legal.

Para tal efecto, se expone una perspectiva multidisciplinaria de los fundamentos conceptuales del sistema de reconocimiento jurídico de la organización de los fieles religiosos, analizando el tránsito desde la etapa comunitaria hacia la forma colectiva de naturaleza social, y desde este a su expresión jurídica en el orden positivo civil. Luego se describe críticamente el régimen legal y reglamentario que rige a las entidades religiosas que gozan de

\footnotetext{
2 Confróntese con Ferrari (1988) p. 345 y Traslosheros (2012) p. 6.

3 Esta tendencia es resaltada por Palomino indicando que al derecho de los Estados y a sus instituciones se adaptan los grupos religiosos, incluyendo su adaptación al concepto de confesión religiosa (Confróntese PALOMINO (2014) p. 83), en tanto que Ferrari concluye que los ordenamientos seculares constituyen "el horizonte jurídico en el que se sitúan todas las comunidades de fieles" (Ferrari (2004), p. 323).
} 
personalidad jurídica de derecho público, abordando su génesis legislativa, su contenido prescriptivo, las distinciones fundamentales y la reglamentación accesoria, para concluir con la evaluación del sistema jurídico vigente utilizando como base las conclusiones extraídas del estudio ya anunciado, titulado "Evaluación del sistema jurídico de reconocimiento del fenómeno religioso en Chile 1999-2013" ción legal de las entidades religiosas chilenas.

\section{LAS COMUNIDADES DE FIELES Y SU TRÁNSITO HACIA COLECTIVIDADES SOCIALES}

Desde una perspectiva antropológica sobre la religión, el concepto de sistemas religiosos brinda una ayuda necesaria para distinguir y caracterizar la actual inserción de los fieles religiosos en el orden social. Los sistemas religiosos están formados por "un conjunto peculiar y complejo de creencias, de ritos, de formas de organización, de sentimientos y de normas éticas" dos o participando en un sistema cultural o subcultural"6.

Aplicando dicha noción a las implicancias mutuas de los creyentes en sus dimensiones individual y grupal, cabe afirmar que las confesiones entendidas como uniones comunitarias en torno a creencias religiosas no son amorfas ni homogéneas, sino que se encuentran caracterizadas por la multiplicidad de tradiciones que se dan cita en ellas ${ }^{7}$, las que siendo recibidas por los sujetos dan lugar a comunidades claramente diferenciadas y cuyo sello distintivo es, precisamente la creencia, asumida como un nexo de carácter natural y no social, vale decir, que incluso el factor volitivo que caracteriza a la organización social pudiera no ser determinante al momento de entender que un individuo es o no parte de una comunidad de signo y fines religiosos. Por lo dicho, es necesario diferenciar el concepto de sistema religioso, de carácter comunitario, y la noción de institucionalidad religiosa de una confesión, que posee un carácter esencialmente social ${ }^{8}$.

\footnotetext{
El estudio corresponde al proyecto de investigación Fondecyt regular $\mathrm{N}^{\circ} 1150705$, el cual contempló como instrumento principal para la obtención de información referida a la constitución jurídica de las entidades religiosas en Chile, una encuesta de carácter nacional de tipo cuantitativo de alcance descriptivo, cuya recolección de datos se efectuó en los años 2015 y 2016. Los resultados, a los cuales se hará referencia en la última parte de este trabajo, se encuentran publicados en el Boletín Jurídico del Observatorio de libertad religiosa de América Latina y el Caribe, de 3 de diciembre de 2016, editado por el Centro UC Derecho y Religión. El análisis completo de dichos resultados se incluye en el artículo titulado "Evaluación del sistema de reconocimiento del fenómeno religioso en Chile 1999-2003”, ya aceptado para su publicación en la Revista Latinoamericana de Derecho y Religión, correspondiente al mes de abril de 2017 y editada por el mismo centro académico.

5 Marzal (2002) pp. 316-317; Marzal (1993) p. 58.

6 Masferrer (2009) p. 32.

7 En palabras de Masferrer, "escindidas, estratificadas y segmentadas por tradiciones culturales, económicas, históricas, religiosas y sociales”. Masferrer (2009) p. 31.

8 Una característica de los sistemas, considerando sus propias dinámicas y la solidaridad que se construye entre miembros de distintas confesiones religiosas, puede determinar que "muchas veces comparten más entre sí que con miembros de otros sectores de la misma comunidad religiosa iglesia a la que pertenecen", poniendo en entredicho los sistemas eclesiales jerarquizados al configurar sistemas de poder laical alternos a las iglesias y sus
} 
Por tal razón, la persona religiosa que adscribe a un movimiento institucional como derrotero lógico de su inserción en la vida social, tiene que adoptar contenidos ajenos y conformarlos de tal manera que los sienta propios ${ }^{9}$, destacando -en línea concordante con Duch- que "las prácticas o las creencias del sujeto religioso moderno son las de alguien que primordialmente se entiende a sí mismo como un ser autónomo... que suele mostrar claras preferencias por la biosfera más que por la socioesfera, lo psicológico más que por lo sociológico", asumiendo una autonomía que se expresa no como un desafío a Dios, sino que a las propias constituciones religiosas y a sus rígidas regulaciones dogmáticas, rituales y morales ${ }^{10}$.

Ahora bien, para explicar cuál es la motivación que induce a formar la organización de fieles y, en definitiva, la agrupación de ellos en función del objetivo religioso, debemos concebir a esta multiplicidad como una unidad, una interacción dentro de la vida social, "distinta del hecho de que en lo múltiple los elementos estén vinculados entre sí y que el destino de cada uno deje imperturbable a los demás"11, no existiendo pleno acuerdo en torno a si su necesidad surge por presión externa al individuo o como una derivación de una toma de conciencia que puede incluso estar motivada por la solidaridad entre aquellos que están implicados en una misma experiencia religiosa, susceptible a su vez de manifestación en niveles de distinta intensidad ${ }^{12}$. Asumiendo que dicha unidad está caracterizada por los elementos individuales que la constituyen, tales elementos separados y móviles para sí mismos dan lugar a una configuración que se vuelve consciente como unidad, al extremo que el individuo, al sentir que él es algo para sí, la fuerza unificadora que lo consolida con los demás se marca fuertemente en un sentido positivo, porque siente que la vida conjunta circunscribe su existencia, o en un sentido negativo, porque en el evento de la oposición, vea a la totalidad como parte enfrentada con sus propios sentires, visiones e intereses ${ }^{13}$.

Las comunidades de fieles se sitúan en el campo social y no en el terreno meramente comunitario y, en tanto organización de naturaleza social, se someten a los requerimientos normativos determinados por la sociedad, vale decir, a los ordenamientos seculares cuya expresión normativa es el derecho, conformado por normas jurídicas cuyo carácter coercitivo las diferencia sustancialmente de las normas religiosas, carentes del recurso a la fuerza pública en caso de inobservancia por parte de los sujetos imperados. Lo anterior adquiere sentido porque, junto con el predominio de una dimensión fundamentalmente personal, en la religión concurre una dimensión colectiva, toda vez que la fe se profesa también ante los hombres y junto con ellos, formando e integrando una comunidad religiosa, con sus

sistemas clericales, generalmente caracterizados por el control que en ellos ejercen especialistas religiosos iniciados en los términos institucionales". Ver Masferrer (2009) p. 31.

9 Considérese Simmel (2013) pp. 21-42.

10 Confróntese con Duch (2002) p. 206.

11 Confróntese con Simmel (2013) p. 62. Sobre la idea de unidad, Simmel afirma que, "en tanto toda la vida social es una interacción es, precisamente por eso, una unidad... pues unidad significa algo distinto del hecho de que en lo múltiple los elementos estén vinculados entre sí y que el destino de cada uno deje imperturbable a los demás" (Simmel (2013) p. 63)

12 Confróntese con Ferrari (1988) p. 345 y Simmel (2013) p. 62.

13 Confróntese con Simmel (2013) p. 63. 
propias necesidades de organización y gobierno ${ }^{14}$. Tal es así en Occidente, desde el predominio de la concepción dualista en el mundo cristiano, que asienta las relaciones de las iglesias con la sociedad política sobre las bases de la distinción entre los campos eclesiástico y político, en que la primera proclama su autonomía para darse una organización y un ordenamiento jurídico propio y original ${ }^{15}$.

La inserción de las comunidades religiosas en el orden jurídico genera importantes efectos adecuatorios de la organización religiosa en el marco social, incidiendo en aspectos importantes que pueden ser identitarios de la confesión, como la forma particular de gobierno interno de la entidad, las denominaciones eclesiales de sus líderes y dirigentes, las jerarquías reconocidas, los requisitos de ingreso y permanencia en la entidad, las causales de expulsión y, en general, toda la armonización del régimen tutelar de derechos del ámbito legal público con aquel orden normativo creado por las organizaciones religiosas, apreciable en los estatutos constitutivos de la persona jurídica y en las declaraciones fundamentales de la confesión religiosa, cuando es exigida como requisito a cumplimentar durante el proceso de reconocimiento civil. En una mirada crítica, los efectos de ajuste pueden ser vistos como parte de una expresión sistemática de adaptación de las religiones a un medio social y jurídico nuevo, proceso también denominado como formateo o estandarización de lo religioso, con efectos ineludibles en la propia confesión ${ }^{16}$.

\section{INSTITUCIONALIZACIÓN DE LA ORGANIZACIÓN RELIGIOSA: DE COLECTIVIDAD SOCIAL A PERSONA JURÍDICA}

La lectura analítica y crítica de la obra de Weber proporciona luces sobre la justificación de la institucionalidad normativa. En su perspectiva, las asociaciones y comunidades religiosas cuando están desarrolladas, dan cuenta de asociaciones de dominación de naturaleza hierocrática entendiendo por tal el régimen de poder caracterizado por el gobierno de los funcionarios religiosos o sacerdotes, cuya fundamentación es de tipo legal y su legitimidad para dar órdenes está basada en reglas que se encuentran establecidas racionalmente, sea que su origen radique en un pacto o en una imposición de autoridad, legitimidad que descansa a su vez en una constitución establecida o interpretada también en forma racional, determinando que el funcionario ejerce el poder de ordenar tras ser habilitado institucionalmente y no como una facultad autónoma ${ }^{17}$. Siendo así, la institucionalización de la organización religiosa es el resultado de la complejización de la experiencia religiosa, lo que a su vez da lugar al surgimiento de organismos dotados de una estructura jurídica propia que expresa en el plano institucional los caracteres de una sociedad igualmente compleja, en

\footnotetext{
14 Confróntese con Santiago (2008) p .43 y Precht (2012) pp. 107-119.

15 Esta afirmación -en el caso de la Iglesia Católica- fue ratificada y desarrollada por el Concilio Vaticano II, cuyos padres conciliares distinguieron las relaciones entre el orden temporal y el religioso, entre la sociedad civil y la sociedad eclesiástica, para concluir en el principio de aquí derivado de la autonomía de los fieles en los asuntos seculares. Compárese Martín De Agar (2014) p. 228 y 238 y Constitución Dogmática "Lumen Gentium” Sobre La Iglesia (1984) pp. 43 y 44.

16 Confróntese con Palomino siguiendo a Roy, en Palomino (2014) p. 79.

17 Confróntese con Weber (2012) p. 374.
} 
donde el problema de su legitimidad de origen y de permanencia constituye una preocupación que reclama constante atención de los fieles ${ }^{18}$.

Los conceptos de lo religioso, siguiendo a Voegelin, han ido a la zaga de las instituciones y sus símbolos, al extremo que hoy en día quien habla de religión piensa en la institución eclesiástica, del mismo modo que quien habla de política piensa en el Estado, comprendiendo la noción de institución una dimensión organizativa en funcionamiento y otra normativa, ambas complementarias, para dar cuenta del comportamiento estabilizado de una agrupación según ciertos esquemas que tienden a su configuración normativa ${ }^{19}$. El proceso de formación del sistema de normas es, sociológicamente, la institucionalización, la que adquiere ribetes públicos cuando se somete y traduce a su vez en normas jurídicas ${ }^{20}$.

Aplicada la noción precedente al estudio de la institucionalidad en su especificidad religiosa, la dimensión organizativa de la religión remite a la satisfacción de aquellas necesidades o funciones que poseen un carácter religioso. En tal caso, se está en presencia de un sistema relativamente estable de funciones, relaciones, valores y normas, comprendiendo esta última dimensión la estabilización y formalización del comportamiento que caracteriza a la experiencia religiosa colectiva, incluyendo en esto el culto, los sistemas doctrinales o corpus de creencias y las prescripciones disciplinares aplicables a la comunidad de fieles ${ }^{21}$.

Sobre la base de lo anterior, la institucionalización de la dimensión social del fenómeno religioso, es necesaria para satisfacer las necesidades e intereses religiosos de la mayoría de las personas, teniendo su expresión corporativa en la noción de entidades religiosas, concepto en el cual se dan cita las dos dimensiones comprendidas en la idea de institución: organización y normativa ${ }^{22}$. En esta perspectiva, es correcto distinguir un ámbito de interacción social en que las confesiones religiosas - devenidas en entidades religiosas- se relacionan con otros actores de la vida política, económica y social de un país, siendo afectadas de forma directa o indirecta por las diferentes fuerzas sociales que se enfrentan en la sociedad, particularmente cuando estas asumen o se constituyen como expresiones de poder, definiendo por tanto una estructura que limita, orienta, motiva y desalienta acciones y actividades relacionadas con el soporte corporativo de las confesiones, es decir, con las personas jurídicas constituidas como tales, siguiendo el patrón establecido por las leyes vigentes.

La inserción en las formas sociales por parte de las comunidades religiosas no es unidimensional, toda vez que los integrantes de un mismo grupo social no reaccionan de la misma manera frente a las dinámicas de globalización e interrelación, por citar dos factores incidentes en dichas decisiones, ya que incluso pueden procurar formas alternas de arti-

\footnotetext{
18 Confróntese con Carlo Jemolo y Silvio Ferrari, en Ferrari (1988) p. 884.

19 Confróntese con Voegelin (2014) pp. 27 y 28.

20 Confróntese con Milanesi, y Cervera (2008) p. 107.

21 Confrontar con Milanesi, y Cervera (2008) p. 109.

22 STARCK (2012) p. 64. Milanesi y Cervera aluden a la distancia entre la simple afiliación jurídica al grupo religioso y el sentimiento psicosociológico de participación en su realidad dinámica (Compárese MilanESI, y Cervera (2008) p. 133 y ss.).
} 
culación y relación con distintos espacios sociales, tal como se aprecia en las comunidades religiosas cristianas en Iberoamérica ${ }^{23}$.

Finalmente, desde una perspectiva política, el reconocimiento de la personalidad jurídica de la organización pública de la agrupación religiosa constituye la forma de recepción de la valoración social del fenómeno religioso en la esfera pública. Dentro de este marco, el tipo concreto de personalidad que se le reconoce a la entidad admite diversas modalidades relacionadas a su vez con las particularidades de cada ordenamiento jurídico, cuyo sistema de relaciones entre Iglesia y Estado es producto de su propia historia, razón por la cual "ningún sistema nacional puede servir como modelo para otro país, si por 'modelo' entendemos algo que debe copiarse" sin filtro alguno que respete la naturaleza especial y diferenciada entre modelo y réplica ${ }^{24}$. La idea de filtro o medio de transición cultural es imprescindible, especialmente cuando el propósito es trasplantar desde una determinada realidad social un modelo jurídico identificado con ella, a otra realidad social, económica y culturalmente diferente.

\section{LA LEY DE CULTOS DE 1999 COMO ORDENAMIENTO JURÍDICO DE LAS CONFESIONES RELIGIOSAS CHILENAS}

Hemos señalado en el apartado precedente que el reconocimiento de la personalidad jurídica de una confesión religiosa, es la forma como se manifiesta la valoración de una sociedad determinada sobre la religión y la organización de sus fieles, particularmente en la esfera pública. De forma correspondiente, el tipo o clase de personalidad civil a la cual puede acceder la comunidad de fieles organizada, las diferencias existentes entre unas y otras desde la perspectiva del Estado y los requisitos para acceder a ella, son también señales distintivas de la valoración pública hacia el fenómeno religioso y sus expresiones sociales organizadas.

Es dentro de este contexto social que debe situarse el régimen jurídico chileno referido al fenómeno religioso y a las entidades religiosas chilenas, erigido a partir de los hitos fundamentales de la separación de la Iglesia y el Estado en la Constitución Política de 1925 y la dictación en 1999 de la ley N 19.638, conocida como Ley de Cultos (LC). Atendiendo la especificidad de este trabajo, nos abocaremos en particular al análisis del régimen legal y reglamentario que rige a las entidades religiosas que gozan de personalidad jurídica de derecho público, abordando su génesis legislativa, contenido, distinciones fundamentales y la reglamentación accesoria, para concluir con la evaluación de la efectividad del sistema vigente, sobre la base principal del estudio de campo cuyas características se detallarán en el apartado siguiente. Lo anterior, a la luz del desarrollo conceptual precedente y del objetivo de analizar el tránsito desde la organización comunitaria a la forma civil concreta, midiendo su eficacia.

\footnotetext{
23 Confróntese con Masferrer (2009) p. 41. Sobre religión y globalización, considérese Palomino Lozano (2014) pp. 32 y ss.

24 Confróntese con Glendon (2012) p. 208.
} 
El régimen jurídico chileno sobre constitución, funcionamiento y disolución de las entidades religiosas reconoce como fuentes formales directas a la Constitución Política de la República, la ley $\mathrm{N}^{\circ} 19.638$ de 1999 y su reglamentación accesoria. Atendiendo la dimensión material del sistema de fuentes, su consideración tiene lugar primero en la determinación del momento en que se produce la aprobación de la ley y la incidencia de factores externos al trabajo legislativo formalmente considerado; y segundo, en el específico contenido prescriptivo que dicha ley materializa. Abordaremos brevemente ambos aspectos.

Respecto de la oportunidad en que se aprobó la ley, su discusión en sede legislativa se desarrolló en forma paralela al asentamiento progresivo de las instituciones democráticas durante el proceso de transición que medió entre el fin del régimen militar y el inicio del nuevo milenio, toda vez que producida la primera elección de autoridades nacionales, la oportunidad se presentó unida no solo al repliegue de la Iglesia Católica desde un protagonismo manifiesto en diversos temas del debate público hacia prioridades ubicadas en el plano estrictamente religioso, sino también debido al interés de los partidos políticos por captar la adhesión de los electores de religión evangélica, los cuales habían aumentado significativamente su número durante los tres quinquenios precedentes, hasta situarse en un porcentaje cercano al quince por ciento del electorado, unido a un cambio relevante en la postura asumida tradicionalmente por los líderes evangélicos, materializada en la unificación de sus esfuerzos individuales y la posterior conformación del Consejo de Organizaciones Evangélicas (COE), organización clave en la aprobación de la ley de 1999.

En cuanto al contenido prescriptivo de la ley, su discusión parlamentaria se extendió por casi diez años, radicando la principal causa de su dilación en las encontradas posturas sobre el carácter del nuevo reconocimiento brindado a las confesiones minoritarias y, principalmente, en las garantías requeridas por las iglesias Católica y Ortodoxa (Patriarcado de Antioquía), en orden a prevenir una afectación de los derechos ya adquiridos, justificados según estas confesiones en su histórico arraigo y en la valoración de su aporte en la construcción republicana por parte de la sociedad chilena.

Junto con la normativa materializada en la ley y sus reglamentos, deben considerarse otras normativas relevantes contenidas en cuerpos legales con finalidades diferentes, pero que abordan en forma parcial materias conectadas con el régimen de las entidades religiosas, tal como ocurre con el derecho matrimonial y el derecho corporativo referido a las personas jurídicas sin fines de lucro. En el primer caso, la conexión de la Ley de Cultos y la Ley de Matrimonio Civil de 2004 ( $\mathrm{N}^{\circ}$ 19.947), es explícita al regular la introducción del reconocimiento civil del matrimonio celebrado en forma. En el segundo caso, debe sumarse la Ley $\mathrm{N}^{\circ} 20.500$, sobre asociaciones y participación ciudadana, que ratifica el reconocimiento de autonomía a los cuerpos sociales intermedios para crear personas jurídicas en función de la satisfacción de sus necesidades corporativas y del logro de los fines propios.

Como fuentes externas de carácter indirecto, cabe destacar el influjo de la Ley Orgánica de Libertad Religiosa (LOLR), de España, relación puesta de manifiesto en repetidas ocasiones durante la tramitación legislativa, sin perjuicio de lo cual el sistema chileno evidencia marcadas diferencias con dicho precedente, tales como la inexistencia de concordato 
entre el Estado y la Santa Sede, la preexistencia del matrimonio civil obligatorio y la temprana separación entre la Iglesia Católica y el Estado en el caso chileno.

La ley $\mathrm{N}^{\circ} 19.638$ regula la organización pública de las confesiones religiosas nacionales, incluyendo el proceso de constitución jurídica, las dimensiones colectiva e individual del principio de libertad religiosa y otras materias ligadas con ambos institutos. Respecto de la constitución jurídica de las organizaciones religiosas, estableció un procedimiento general aplicable a todas las confesiones, a la vez que consagró normativamente y de modo expreso en el artículo 20, el reconocimiento del régimen precedente de todas las entidades preexistentes, extensivo a su naturaleza jurídica, con lo cual dilucidó cualquier duda que pudiere subsistir respecto del régimen aplicable a la Iglesia Católica Romana. En ambos casos, el resultado es el reconocimiento de la personalidad jurídica de derecho público de las principales expresiones religiosas chilenas, configurando un avance sustancial en materia de protección jurídica de la libertad religiosa y en el afianzamiento de la igualdad de los distintos cultos religiosos ante la ley.

En términos generales, la ley regula dos cuestiones fundamentales: la consagración en el nivel legal del principio de libertad religiosa en un plano bidimensional y el establecimiento de un procedimiento que conduce al reconocimiento de la personalidad jurídica de derecho público, sobre la base de su inscripción en el registro público del Ministerio de Justicia, seguida de la publicación de un extracto del acta de constitución en el Diario Oficial. En este segundo aspecto el régimen se caracteriza por la ausencia de controles sustantivos y por la posibilidad de crear personas jurídicas derivadas.

La ley ha tratado deferentemente a las confesiones con reconocimiento histórico, a saber la Iglesia Católica y la Iglesia Ortodoxa, lo que se explica y justifica no solo en el reconocimiento de los derechos históricamente adquiridos y la relevancia social de ambas confesiones, sino también como una forma de diluir la oposición inicial a la aprobación del proyecto de ley por parte de sectores ligados a la Iglesia Católica, quienes hicieron presente por diferentes vías que las normas del proyecto colisionaban abiertamente con las prerrogativas que históricamente le habían sido reconocidas a esta iglesia, desconociendo además -según su apreciación- las diferencias efectivas entre las confesiones con presencia histórica y aquellas constituidas más recientemente, cuyo igual tratamiento irrogaba un perjuicio evidente, a los ojos de los detractores. La cuestión se zanjó mediante una indicación sustitutiva del proyecto original, previamente consensuada en la Cámara, y que derivó en la inclusión de una norma contenida en el artículo 20 de la Ley $\mathrm{N}^{\circ} 19.638$, en virtud de la cual el Estado reconocía, "el ordenamiento, la personalidad jurídica, sea esta de derecho público o de derecho privado, y la plena capacidad de goce y ejercicio de las iglesias, confesiones e instituciones religiosas que los tengan a la fecha de publicación [de la ley]...”. Por tanto, la anhelada igualdad jurídica se tradujo en una asimilación del estatus de las entidades minoritarias al que ya era reconocido a la Iglesia Católica.

A la ley 19.638 se sumaron luego cuatro reglamentos específicos sobre materias accesorias a la ley, cuya entrada en vigor se produjo en los años siguientes, constituyendo en conjunto la respuesta de la sociedad política a la demanda de igualación de las confesiones minoritarias y a la voluntad de relevar el tratamiento jurídico del fenómeno religioso por parte del Estado. Los reglamentos han normado la ejecución del procedimiento condu- 
cente al reconocimiento de la personalidad jurídica y el ejercicio del derecho a la asistencia religiosa de las personas en situaciones de excepcionalidad. Sin perjuicio de la especificidad regulatoria centrada en la asistencia religiosa en cárceles, recintos hospitalarios y en recintos militares y policiales, los reglamentos rozaron tres cuestiones de mayor alcance, a saber, la institución de las capellanías, la responsabilidad patrimonial del Estado y la objeción de conciencia, materias de notoria significación social y jurídica.

Durante el período de vigencia de la ley 19.638, el régimen legal chileno aplicado al fenómeno religioso en su expresión social ha sido objeto del beneplácito de algunos sectores de opinión, así como también de fuertes críticas. Entre quienes sustentan la primera perspectiva, ha existido coincidencia en valorar la liberalidad del sistema instituido, su profunda significación para las minorías religiosas y la efectividad de sus normas basada en su validación cuantitativa, al superar las dos mil quinientas entidades religiosas reconocida al momento concluir este estudio. En la segunda perspectiva, los detractores parciales o totales del sistema han concentrado sus críticas en el carácter a su juicio extremadamente liberal del sistema instituido, en cuestionar la calidad de derecho público de la personalidad reconocida, eventuales imperfecciones en la técnica legislativa, al nulo control de las entidades sectarias, a la proliferación de entidades y a la ausencia de normas adecuatorias con la legislación común que faciliten su aplicación armónica. Este debate, que ya había acompañado tempranamente la discusión en sede parlamentaria, da cuenta de la persistencia de criterios jurídicos interpretativos basados en opciones finalistas contrapuestas o insuficientemente concordadas, que en distinto grado podrían afectar el necesario desarrollo en extensión y profundidad del sistema cuya positiva valoración se admite.

En síntesis, se ha planteado que las comunidades de fieles se insertan en el orden secular materializado en el derecho vigente que reconoce personalidad civil a las comunidades de fieles organizadas. En Chile, dicho orden especial ha surgido de la aprobación de la ley 19.638, de 1999, respecto de la cual han existido opiniones contrapuestas sobre diferentes aspectos, pero sobre su efectividad organizacional no habría espacio para dudas, en especial si se atiende a las más de dos mil entidades reconocidas, pertenecientes a las más diversas tradiciones religiosas. En tal sentido, el sistema instituido ha sido efectivo en términos de posibilitar la constitución de entidades religiosas con personalidad jurídica de derecho público, del progreso significativo de los espacios de libertad y tolerancia y de la valoración del derecho de libertad religiosa, sin perjuicio de adolecer de algunas lagunas e imperfecciones legislativas que ameritan una revisión crítica de la normativa y de su impacto, para verificar las condiciones de consolidación de un sistema cuya principal característica es su alta significación para una parte importante de la ciudadanía.

\section{EFICACIA DEL RÉGIMEN ESTABLECIDO POR LA LEY N 19.638 Y SU REGLAMENTACIÓN ACCESORIA}

Considerando que el régimen instaurado a contar de 1999 constituye la expresión jurídica de la valoración social sobre el fenómeno religioso en Chile, en particular de su dimensión asociativa, procede en este último apartado dedicar atención a la eficacia del 
mismo, vale decir, a establecer si el conjunto normativo constituido por la LC y sus reglamentos enmarcado en el contexto constitucional ha sido efectivo en cuanto a constituir el modo en que las comunidades de fieles se organizan socialmente, abordando su utilización por parte de las confesiones religiosas socialmente organizadas y el grado de satisfacción que estas declaran al comparar la realidad con las expectativas iniciales en torno a dicho régimen.

La evaluación de la eficacia de la LC, en el marco previamente indicado, la hemos basado principalmente en los resultados obtenidos del estudio titulado "Evaluación del sistema de reconocimiento del fenómeno religioso en Chile 1999-2013", realizado bajo nuestra responsabilidad, el cual consideró una muestra de 179 observaciones y cuyos resultados ya han sido difundidos en el Boletín Jurídico Observatorio de Libertad Religiosa de América Latina y el Caribe, publicación que servirá como fuente de las referencias que se realizarán a continuación ${ }^{25}$.

\section{A. Caracterización general de las confesiones religiosas chilenas}

La generalidad de las entidades religiosas legalmente constituidas en Chile se declaran cristianas o admiten su consideración como parte integrante de la tradición cristiana, caracterizándose el sistema por la presencia de dos grandes comunidades pertenecientes a esta tradición: una mayoritaria constituida por los fieles de la Iglesia Católica, y una importante minoría constituida por los fieles de las iglesias evangélicas, sin que sea pertinente calificar a la sociedad chilena como biconfesional, pero sí de carácter multirreligiosa. Las comunidades o grupos no cristianos son minoritarios dentro del conjunto formado por las entidades religiosas con reconocimiento civil, toda vez que excepcionalmente algunos entrevistados señalan su adscripción o pertenencia a corrientes o familias religiosas no cristianas, recibiendo mención las confesiones budista, judía e hindú.

25 Toda la información utilizada, expresada en tablas y gráficos, debe entenderse referida al estudio indicado, el cual se incluye en forma íntegra en el "Boletín Jurídico Observatorio de Libertad Religiosa de América Latina y el Caribe”, número 3, de diciembre de 2016, editado por el Centro UC Derecho y Religión. Dichos resultados son arrojados por una encuesta nacional aplicada a representantes de entidades religiosas inscritas en el Registro de Entidades Religiosas de Derecho Público, del Ministerio de Justicia de Chile, correspondiente a un estudio de tipo cuantitativo de alcance descriptivo, cuya recolección de datos se realizó a través de un muestreo no probabilístico por conveniencia, con entrevista cara a cara a líderes o encargados de entidades religiosas de derecho público según criterios de selección predeterminados, referidos a concentración de población, número de entidades registradas, inclusión de confesiones con arraigo histórico, inclusión del mayor número posible de tradiciones religiosas y amplia distribución geográfica territorial. Las conclusiones consideran calificadores cualitativos definidos por el autor, en que se aplican los conceptos "significativo" cuando las respuestas favorables a las preguntas superan el $20 \%$ de los entrevistados, "mayoritaria" cuando supera el 50\%, "generalizada" cuando es superior al 75\% y "unánime" cuando supera el 98\%, asignando para este último factor un margen de error de un $2 \%$. El análisis completo de los resultados, con referencia directa a la información expresada en gráficos y tablas, se incluye en el artículo titulado "Evaluación del sistema de reconocimiento del fenómeno religioso en Chile 1999-2003", ya aceptado para su publicación en la Revista Latinoamericana de Derecho y Religión, correspondiente al mes de abril de 2017, editada por el Centro UC Derecho y Religión. 
Del Picó Rubio, Jorge $\llbracket$ La inserción de las comunidades de fieles en los ordenamientos seculares...

B. Igualdad Jurídica de las ENTidades RELigiosas EN EL Sistema LeGAL. PERCEPCIÓN DE SUPERACIÓN DE INEQUIDADES HISTÓRICAS

Respecto de las dos comunidades mayoritarias, cabe señalar que pese a la histórica desavenencia entre las comunidades cristianas católica y evangélica, en la actualidad sus diferencias aparecen notoriamente reducidas, pudiendo destacarse que la apreciación actual de los evangélicos sobre la persistencia de la inequidad de trato prodigada por el Estado hacia sus iglesias, es significativamente menor que lo previsto en estudios doctrinarios precedentes a este estudio, y casi inexistente en entidades cristianas protestantes históricas (luteranos, anglicanos, entre otras) y en aquellas entidades que se definen como no cristianas (ver Tabla 1).

Tabla 1: Corriente religiosa a la que adscribe

\begin{tabular}{|l|l|l|}
\hline Categorías & Frecuencia & Porcentaje \\
\hline Cristiana & 172 & $96,1 \%$ \\
\hline No Cristiana & 7 & $3,9 \%$ \\
\hline \hline TOTAL & 145 & $100,0 \%$ \\
\hline
\end{tabular}

Fuente: Del Picó (2016).

Sin embargo, si se considera a quienes defienden que tales diferencias persisten, una minoría significativa cercana a la mitad de quienes sustentan dicha visión, fundamentan su juicio en la ausencia de un cambio importante que haya beneficiado de un modo efectivo a sus iglesias y comunidades religiosas, destacando negativamente que, en los hechos, se habrían mantenido inalterados los privilegios que históricamente han beneficiado a la Iglesia Católica Romana (ver Tablas 2 y 3).

Tabla 2: Valoración de diferentes aspectos para una mirada favorable del sistema

\begin{tabular}{|c|c|c|c|c|}
\hline \multirow[t]{2}{*}{ CATEGORÍAS } & \multicolumn{4}{|l|}{ VALORACIÓN } \\
\hline & No lo valoro & $\begin{array}{l}\text { Lo valoro } \\
\text { poco }\end{array}$ & Lo valoro & $\begin{array}{l}\text { Lo valoro } \\
\text { mucho }\end{array}$ \\
\hline $\begin{array}{l}\text { 1. Terminó con la desigualdad entre mi iglesia y la iglesia católica } \\
\text { romana }\end{array}$ & 26,4 & 18,1 & 31,9 & 23,6 \\
\hline 2. Permitió gozar de personalidad de derecho público & 0 & 4,2 & 36,1 & 59,7 \\
\hline 3. No quedo sometido a la arbitrariedad del gobierno de turno & 5,6 & 12,5 & 31,9 & 50,0 \\
\hline $\begin{array}{l}\text { 4. Permite usar las denominaciones que nos son más cercanas, como } \\
\text { obispo en vez de presidente, e iglesia en vez de corporación }\end{array}$ & 5,6 & 8,5 & 38,0 & 47,9 \\
\hline 5. Permite que hayan capellanes de mi iglesia & 15,3 & 9,7 & 26,4 & 48,6 \\
\hline 6. Permite administrar mejor los bienes de la iglesia & 7,0 & 7,0 & 38,0 & 47,9 \\
\hline 7. Socialmente se nos mira con mejores ojos & 8,5 & 12,7 & 36,6 & 42,3 \\
\hline 8. Significa que se respeta más a todas las religiones, sin discriminar & 8,5 & 16,9 & 33,8 & 40,8 \\
\hline
\end{tabular}

Fuente: Del Picó (2016) 
Tabla 3: Razón para considerar que el cambio del DS 110 a la Ley de Cultos es desfavorable

\begin{tabular}{|l|l|l|}
\hline Categorías & Frecuencia & Porcentaje \\
\hline No implica un cambio significativo & 8 & $47,1 \%$ \\
\hline No ha cambiado nada & 1 & $5,9 \%$ \\
\hline $\begin{array}{l}\text { Ha dificultado el traspaso de los bienes de la corporación anterior a la iglesia de derecho } \\
\text { público }\end{array}$ & 1 & $5,9 \%$ \\
\hline No contempla la objeción de conciencia & 1 & $5,9 \%$ \\
\hline No están claros los beneficios tributarios & 1 & $5,9 \%$ \\
\hline $\begin{array}{l}\text { Se mantiene la discriminación respecto de la religión de la mayoría, que sigue gozando de } \\
\text { privilegios }\end{array}$ & 5 & $29,4 \%$ \\
\hline \hline TOTAL & 17 & $100,0 \%$ \\
\hline
\end{tabular}

Fuente: DeL PICÓ (2016).

\section{EFICACIA LEGAL: CONOCIMIENTO DEL RÉGIMEN APLICABLE}

El régimen legal que rige a las comunidades religiosas tiende a ser considerado como un tema particularmente complejo, árido y de no fácil acceso para la mayor parte de los líderes de las comunidades religiosas, siendo especialmente notorio en el caso de las iglesias evangélicas pentecostales, integradas por personas tradicionalmente reacias a la participación eclesial en el ámbito público, ya sea por tratarse de una opción derivada de la propia convicción religiosa dualista sobre los ámbitos propios de competencia de la iglesia y el Estado, o por haber sido discriminadas social y políticamente durante los años precedentes a la entrada en vigor de la LC. Teniendo presente lo anterior, una primera medida de la eficacia legislativa debe considerar en primer lugar el grado de conocimiento de las leyes por parte de los sujetos imperados, especialmente de los destinatarios preferentes de dicha normativa.

En tal sentido, la mayoría de los representantes de las entidades religiosas conocen de un modo general el ordenamiento jurídico que rige a las entidades religiosas en Chile, incluyendo como cuerpos normativos principales a la Constitución Política de la República y a la Ley $\mathrm{N}^{\circ} 19.638$ (Ley de Cultos). Un número significativo señala tener un conocimiento solo parcial del ordenamiento jurídico que rige a sus entidades, en tanto que respecto de la vía legal y de la relevancia del ordenamiento secular como organización de las comunidades de fieles, la generalidad de los representantes de las entidades religiosas declara conocer lo que significa la personalidad jurídica $(89,9 \%)$, resultado que si bien debe ser considerado positivo, también debe destacarse el hecho que una décima parte de los entrevistados declaren ignorar dicho significado, proporción que proyectada al conjunto de las entidades religiosas inscritas en el Registro de Entidades Religiosas de Derecho Público, da cuenta que los representantes de, al menos, doscientas entidades ya inscritas no tendrían conocimiento del concepto de personalidad jurídica y consecuencialmente de sus efectos positivos y eventualmente negativos.

Por tanto, debe destacarse la relevancia de las vías normadas y su amplia apreciación y utilización por las confesiones religiosas, subsistiendo un reducido pero significativo déficit en el conocimiento efectivo de los institutos normativos en particular (ver Tablas 4,5 y 6$)$. 
Del Picó Rubio, Jorge $\square$ La inserción de las comunidades de fieles en los ordenamientos seculares...

Tabla 4: Conoce las leyes que rigen a las iglesias y comunidades religiosas

\begin{tabular}{|l|l|l|}
\hline Categorías & Frecuencia & Porcentaje \\
\hline Sí, las conozco en general & 91 & $50,8 \%$ \\
\hline No las conozco & 11 & $6,1 \%$ \\
\hline Sólo alguna de ellas & 61 & $34,1 \%$ \\
\hline No entiendo el tema legal & 7 & $3,9 \%$ \\
\hline Prefiero no emitir respuesta & 9 & $5,0 \%$ \\
\hline \hline TOTAL & 179 & $100,0 \%$ \\
\hline
\end{tabular}

Fuente: DeL PICÓ (2016)

Tabla 5: Ley de culto que aplica en entidad religiosa

\begin{tabular}{|l|l|l|}
\hline Categorías & Frecuencia & Porcentaje \\
\hline Ley de Cultos & 147 & $83,1 \%$ \\
\hline Constitución Política de la República & 67 & $37,9 \%$ \\
\hline Ley N 19.638 & 59 & $33,3 \%$ \\
\hline Ley N 20.500 & 20 & $11,3 \%$ \\
\hline Decreto Supremo N ${ }^{\circ} 110$ & 19 & $10,7 \%$ \\
\hline Desconozco la materia & 15 & $8,5 \%$ \\
\hline \hline TOTAL & 262 & $184,7 \%$ \\
\hline
\end{tabular}

Fuente: Del Picó (2016)

Tabla 6: Conoce lo que es personalidad jurídica

\begin{tabular}{|l|l|l|}
\hline Categorías & Frecuencia & Porcentaje \\
\hline Sí & 161 & $89,9 \%$ \\
\hline No & 18 & $10,1 \%$ \\
\hline \hline TOTAL & 179 & $100,0 \%$ \\
\hline
\end{tabular}

Fuente: Del Picó (2016)

En cuanto a la normativa accesoria de la Ley de Cultos, el reglamento de asistencia religiosa mejor valorado, en su actual redacción, es el Reglamento de Asistencia Religiosa en Recintos de las Fuerzas Armadas y de Orden y Seguridad Pública, seguido por el Reglamento de Asistencia Religiosa en Recintos Penitenciarios y similares. El reglamento menos valorado en su actual redacción, y que requeriría necesariamente ajustes a la luz de los reparos observados, es el Reglamento de Asistencia Religiosa en Recintos Hospitalarios (ver Tabla 7). 
Tabla 7: Conocimiento y/o aplicación de algunos reglamentos

\begin{tabular}{|l|l|l|}
\hline Categorías & Frecuencia & Porcentaje \\
\hline Reglamento de asistencia religiosa en hospitales y clínicas & 134 & $75,3 \%$ \\
\hline Reglamento de asistencia religiosa en establecimientos penitenciarios & 89 & $50,0 \%$ \\
\hline No los conoce/No ha aplicado reglamento & 34 & $19,1 \%$ \\
\hline Reglamento de asistencia religiosa en establecimientos de las FFAA y Policía & 33 & $18,5 \%$ \\
\hline \hline TOTAL & 290 & $162,9 \%$ \\
\hline
\end{tabular}

*Nota: Pregunta con respuesta múltiple, por lo que el total es mayor a 100

Fuente: Del Picó (2016)

\section{EFICACIA UTILITARIA DEL RÉGIMEN LEGAL POR PARTE DE LAS ENTIDADES}

En cuanto a la eficacia de la Ley de Cultos en materia de constitución jurídica de las entidades religiosas, la mayoría de las colectividades chilenas se organizaron jurídicamente luego de la entrada en vigor de la LC, adecuándose a sus disposiciones normativas, sin perjuicio de consignar que una minoría significativa ya gozaba de personalidad jurídica de derecho privado al amparo de las normas del sistema vigente con anterioridad. La generalidad de las entidades religiosas existentes en 1999, optaron por modificar su naturaleza jurídica, sometiéndose al procedimiento establecido por las disposiciones de la LC (ver Tablas 8, 9 y $10)$.

Tabla 8: Cuándo se organizó su iglesia o comunidad religiosa

\begin{tabular}{|l|l|l|}
\hline Categorías & Frecuencia & Porcentaje \\
\hline Antes de 1999 & 68 & $38,0 \%$ \\
\hline En 1999 & 7 & $3,9 \%$ \\
\hline Después de 1999 & 103 & $57,5 \%$ \\
\hline NS/NR & 1 & $0,6 \%$ \\
\hline \hline TOTAL & 179 & $100,0 \%$ \\
\hline
\end{tabular}

Fuente: Del Picó (2016)

Tabla 9: Tras aprobarse ley de cultos cambió personalidad jurídica

\begin{tabular}{|l|l|l|}
\hline Categorías & Frecuencia & Porcentaje \\
\hline Sí & 59 & $86,8 \%$ \\
\hline No & 4 & $5,9 \%$ \\
\hline $\begin{array}{l}\text { Está pendiente en su decisión por parte de la asamblea u otro órgano } \\
\text { similar de la iglesia/comunidad religiosa }\end{array}$ & 1 & $1,5 \%$ \\
\hline Es una materia que desconozco & 4 & $5,9 \%$ \\
\hline \hline TOTAL & 68 & $100,0 \%$ \\
\hline
\end{tabular}

Fuente: Del Picó (2016) 
Del Picó Rubio, Jorge $\square$ La inserción de las comunidades de fieles en los ordenamientos seculares...

Tabla 10: Cuándo obtuvo personalidad jurídica

\begin{tabular}{|l|l|l|}
\hline Categorías & Frecuencia & Porcentaje \\
\hline Antes de noviembre de 1999 & 30 & $18,6 \%$ \\
\hline Después de noviembre de 1999 & 130 & $80,7 \%$ \\
\hline NS/NR & 1 & $0,6 \%$ \\
\hline \hline TOTAL & 161 & $100,0 \%$ \\
\hline
\end{tabular}

Fuente: DEL PICÓ (2016)

La mayoría de los entrevistados considera que la LC permite solucionar problemas prácticos de las entidades religiosas, siendo irrelevante la opinión de quienes sostienen lo contrario o que consideran que existen trabas innecesarias. La mayoría de las entidades religiosas que mutaron la naturaleza de su personalidad jurídica de derecho privado a derecho público también considera que el proceso normado que posibilita la transferencia de bienes entre la persona jurídica antecedente de aquella que goza de personalidad jurídica de derecho público ha sido dificultoso (ver Tabla 11).

Tabla 11: Traspaso de bienes desde derecho privado a derecho público

\begin{tabular}{|l|l|l|}
\hline Categorías & Frecuencia & Porcentaje \\
\hline Muy fácil & 5 & $2,8 \%$ \\
\hline Fácil & 30 & $16,8 \%$ \\
\hline Difícil & 25 & $14,0 \%$ \\
\hline Muy difícil & 11 & $6,1 \%$ \\
\hline No fuimos iglesia de derecho privado & 102 & $57,0 \%$ \\
\hline NS/NR & 6 & $3,4 \%$ \\
\hline \hline TOTAL & 179 & $100 \%$ \\
\hline
\end{tabular}

Fuente: Del Picó (2016)

Sin perjuicio de lo consignado en el número precedente, una parte mayoritaria de las entidades que actualmente gozan de personalidad jurídica de derecho público, considera que la LC brinda demasiadas facilidades para la constitución jurídica de las entidades religiosas, especialmente si se consideran los escasos requisitos exigidos por la ley para constituirlas. Esta opinión es, sin duda, contradictoria con los planteamientos sostenidos durante el período de tramitación parlamentaria de la ley por los líderes de las confesiones minoritarias, pudiendo en parte ser explicada por los procesos de división que caracterizan a algunas tradiciones eclesiales protestantes (Ver Tablas 11 y 12).

Tabla 12: Grado de acuerdo con afirmaciones respecto de la Ley de Cultos

\begin{tabular}{|l|l|l|l|l|l|}
\hline \multirow{2}{*}{ CATEGORÍAS } & \multicolumn{3}{l|}{ NIVEL DE ACUERO } & \multicolumn{3}{l|}{ Nideacuerdonien } \\
\cline { 2 - 7 } & $\begin{array}{l}\text { Muy en } \\
\text { desacuerdo }\end{array}$ & $\begin{array}{l}\text { En } \\
\text { descuerdo }\end{array}$ & $\begin{array}{l}\text { Muy de } \\
\text { acuerdo }\end{array}$ \\
\hline $\begin{array}{l}\text { La ley de cultos permite solucionar problemas } \\
\text { prácticos del funcionamiento de la iglesia o } \\
\text { comunidad religiosa }\end{array}$ & $3,9 \%$ & $8,4 \%$ & $32,6 \%$ & $35,4 \%$ & $19,7 \%$ \\
\hline $\begin{array}{l}\text { La Ley de Cultos otorga demasiadas facilidades } \\
\text { para la creación de iglesias }\end{array}$ & $5,6 \%$ & $11,9 \%$ & $18,1 \%$ & $25,4 \%$ & $39,0 \%$ \\
\hline
\end{tabular}

Fuente: Del Picó (2016) 
Finalmente, en lo que a este aspecto respecta, cabe destacar que el régimen legal admite diversas alternativas para reconocer civilmente a las entidades religiosas, toda vez que si bien la normativa especial de la ley 19.638 constituye la opción privilegiada por el legislador, con evidentes beneficios comparativos respecto del sistema anterior, la migración desde el sistema antiguo al nuevo no es obligatoria, determinando la ley que, incluso, no podrá existir discriminación por parte del Estado entre entidades religiosas constituidas al amparo de la antigua ley y aquellas que opten por constituirse como personas jurídicas de derecho público al amparo de las normas de la LC.

\section{E. AdAPTACIÓN DE LAS ORGANIZACIONES RELIGIOSAS A UN MEDIO SOCIAL Y JURÍDiCO NUEVO \\ El tránsito de las organizaciones religiosas desde una forma comunitaria a otra} de naturaleza social implica necesariamente un proceso de adaptación por parte de estas colectividades a un medio social y jurídico enteramente nuevo, no exento de dificultades de distinto grado. El sistema chileno, sin embargo, facilita dicho camino al contemplar como principio informador del orden normativo especial a la autonomía reconocida a las entidades religiosas para darse a sí mismas las denominaciones, el gobierno y la estructura organizacional que estimen más adecuada a sus necesidades y a las particularidades de la propia confesión religiosa, facilitando de este modo los ajustes y adecuaciones requeridos.

Asimismo, se debe destacar que la posibilidad de gozar del reconocimiento de personalidad jurídica de derecho público para las entidades religiosas es la causa más relevante en la buena apreciación casi unánime que estas colectividades tienen de la LC (ver Tabla 2), siendo dentro de sus disposiciones muy valorada de manera general la autonomía institucional, expresada en la facultad de los miembros de una entidad religiosa para adoptar la organización administrativa que estimen más adecuada a la naturaleza de su institución y de poder establecer y utilizar las denominaciones eclesiásticas propias por parte de todas ellas.

\section{F. Satisfacción de los Usuarios}

Respecto de la evaluación general de la situación actual de las entidades religiosas chilenas, la mayoría de los representantes de las entidades religiosas considera que la LC ha sido un avance en la libertad religiosa en Chile, siendo significativamente superior la opinión favorable respecto del mejoramiento de la situación de las entidades religiosas en Chile luego de la entrada en vigor de la LC. Asimismo, es generalizada la opinión de quienes consideran que la situación de las entidades religiosas chilenas es igual o mejor que antes de la dictación de la LC, ya que las entidades religiosas constituidas con anterioridad a 1999 consideran mayoritariamente que el régimen legal surgido de la reforma es mejor que el régimen precedente (ver Tablas 13 y 14). 
Del Picó Rubio, Jorge $\square$ La inserción de las comunidades de fieles en los ordenamientos seculares...

Tabla 13: Situación general luego de entrada en vigencia de la Ley de Cultos

\begin{tabular}{|l|l|l|}
\hline Categorías & Frecuencia & Porcentaje \\
\hline Mejor que antes & 88 & $49,2 \%$ \\
\hline Igual que antes & 83 & $46,4 \%$ \\
\hline Peor que antes & 8 & $4,5 \%$ \\
\hline \hline TOTAL & 179 & $100 \%$ \\
\hline
\end{tabular}

Fuente: Del PICó (2016)

Tabla 14: Considera que el actual régimen es mejor que el anterior

\begin{tabular}{|l|l|l|}
\hline Categorías & Frecuencia & Porcentaje \\
\hline Sí & 72 & $40,2 \%$ \\
\hline No & 17 & $9,5 \%$ \\
\hline No se encontraba organizada en base a DS 110 & 89 & $49,7 \%$ \\
\hline NS/NR & 1 & $0,6 \%$ \\
\hline \hline TOTAL & 179 & $100 \%$ \\
\hline
\end{tabular}

Fuente: Del PICó (2016)

\section{G. EFICACIA LEGISLATIVA}

La Ley $\mathrm{N}^{\circ} 19.638$, en su denominación popular como Ley de Cultos, es el cuerpo jurídico principalmente conocido y aplicado por las confesiones religiosas chilenas, confirmando el estudio que la ley y su entrada en vigor en 1999, constituye el hito o punto de inflexión de la apreciación por parte de las confesiones minoritarias del cambio en materia de igualdad de trato del Estado chileno hacia las entidades religiosas no mayoritarias, siendo su eficacia legislativa, desde el punto de vista de las minorías, evidente.

\section{CONCLUSIONES}

1. Las confesiones entendidas como uniones comunitarias en torno a creencias religiosas se caracterizan por la multiplicidad de tradiciones que concurren en ellas, dando lugar a comunidades diferenciadas entre sí y con necesidades igualmente diferentes, lo que explica las dificultades que encierra el tránsito desde las formas comunitarias a las formas sociales jurídicas realizado por las colectividades religiosas.

2. Las comunidades de fieles en tanto organizaciones de naturaleza social, deben adecuarse a los requerimientos normativos determinados por la sociedad u ordenamientos seculares, cuya expresión normativa es el derecho.

3. El ordenamiento secular de naturaleza jurídica dispuesto para la organización civil de las comunidades de fieles en Chile es la ley $\mathrm{N}^{\circ} 19.638$ y su normativa accesoria, conjunto normativo que ha tenido un impacto favorable desde la perspectiva de las confesiones religiosas beneficiadas por sus normas, especialmente las iglesias evangélicas y otras confesiones religiosas minoritarias, particularmente por el reconocimiento de su organización social bajo el principio informador de la autonomía. 
4. La inserción de las comunidades religiosas en el orden jurídico genera importantes efectos adecuatorios de la organización religiosa en el marco social, incidiendo en aspectos importantes que pueden afectar incluso la identidad de la confesión.

5. Los conceptos sobre el fenómeno religioso admiten un claro influjo institucional, comprendiendo la noción de institución una dimensión organizativa en funcionamiento y otra de carácter normativo.

6. Las confesiones religiosas organizadas como entidades religiosas poseen un ámbito de interacción social dinámico, en virtud del cual se relacionan con otros actores de la vida política, económica y social de un país, sin poder evitar ser afectadas de modo directo o indirecto por el conflicto social.

7. Desde una perspectiva político-jurídica, el reconocimiento de la personalidad jurídica de la organización religiosa constituye la forma de recepción de la valoración social del fenómeno religioso en la esfera pública.

\section{BIBLIOGRAFÍA CITADA}

Constitución Dogmática "Lumen Gentium” Sobre La Iglesia, 31 (1984), en Documentos completos del Vaticano II (Bilbao, Mensajero, 12a . ed.) pp. 43-44.

Del Picó, Jorge (2016): "Percepción de satisfacción con el régimen legal de las iglesias y entidades religiosas en Chile", Boletín Jurídico Observatorio de libertad religiosa de América Latina y el Caribe, Año XII No 3: pp. 89-120.

DuCH, Luis (2002): La religión en el siglo XXI (Madrid, Siruela).

Ferrari, Silvio (2004): El espiritu de los derechos religiosos (trad. de G. Canal Marcos, Barcelona, Herder).

Ferrari, Silvio (1998): voz "Política eclesiástica”, en Bobbio, Norberto y MatTeuCCI, Nicola, Diccionario de política (tomo II), (Ciudad de México, Siglo XXI Editores, 5 ta. Edición en español) p. 345.

Glendon, Mary Ann (2012): "Estado laico y libertad religiosa”, en Traslosheros, Jorge (coord.), Libertad religiosa y Estado laico. Voces, fundamentos y realidades, (Porrúa, México) p. 208.

Martín De Agar, José (2014): Introducción al derecho canónico (Madrid, Tecnos, segunda edición).

MARZAL, Manuel (1993): "Sincretismos religiosos latinoamericanos", en Gómez, José (Editor), Religión (Madrid, Trotta) pp. 55-68.

MARZAL, Manuel (2002): Tierra encantada. Tratado de antropología religiosa de América Latina (Trotta, Madrid).

MASFERRER, Elio (2009): Religión, poder y cultura: ensayo sobre la política y la diversidad de creencias (Buenos Aires, Libros de la Araucaria S.A.).

Milanesi, Giancarlo y Cervera, Joaquim (2008): Sociología de la religión (trad. Arcadio Cuadrado, Madrid, CCS).

Palomino Lozano, Rafael (2014): Neutralidad del Estado y espacio público (Pamplona, Editorial Aranzadi, S.A.). 
Del Picó Rubio, Jorge — La inserción de las comunidades de fieles en los ordenamientos seculares...

Precht, Jorge (2012): “Secularización, laicidad y libertad religiosa en Chile”, en Traslosheros, Jorge (Coord.), Libertad religiosa y Estado laico (México, Porrúa) pp. 107-119

Santiago, Alfonso (2008): Religión y politica (Buenos Aires, Ad-Hoc).

Simmel, Georg (2013): La religión (Barcelona, Gedisa).

STARCK, Christian (2012): "La libertad religiosa en Alemania como libertad positiva y negativa”, en Elósegui ItxAso, María (coord.), La neutralidad del Estado y el papel de la religión en la esfera pública en Alemania (Zaragoza, Fundación Manuel Giménez Abad) p. 64.

Traslosheros, Jorge (2012): "Fundamentos de la libertad religiosa", en IDEM, Libertad religiosa y Estado laico (México, Porrúa) p. 6.

Voegelin, Eric (2014): Las religiones politicas, (trad. de Manuel Abella y Pedro García Guirao, Madrid, Trotta).

Weber, Max (2012): Sociología de la religión, (trad. de Enrique Gavilán, Madrid, Akal, segunda edición).

\section{NORMATIVA CITADA}

Constitución Política de la República de Chile (18/9/1925)

Constitución Política de la República de Chile (21/10/1980)

LeY N ${ }^{\circ} 19.638$ (14/10/1999). Ley de Cultos. Establece Normas sobre la Constitución Jurídica de las Iglesias y Organizaciones Religiosas.

Ley N 19.947 (17/5/2004). Nueva Ley de Matrimonio Civil.

Ley N 20.500 (16/2/2011). Sobre Asociaciones y Participación Ciudadana en la Gestión Pública.

LeY Orgánica 7/1980 (5/7/1980). Sobre Libertad Religiosa (LOLR) en España. 